\title{
REFLEXÕES SOBRE O PLANEJAMENTO EM SAÚDE E O PROCESSO DA REFORMA SANITÁRIA BRASILEIRA
}

\author{
Francisco Carlos Félix Lana * \\ Elizabeth Laus Ribas Gomes **
}

LANA, F.C.F., GOMES, E.L.R. Reflexões sobre o planejamento em saúde e o processo da reforma sanitária brasileira. Rev.latino-am.enfermagem, Ribeirão Preto, v. 4, n. 1, p. 97-110, janeiro 1996.

Neste trabalho. os autores procuraram desenvolver algumas reflexões sobre as formulações das políticas sociais brasileiras nos regimes populista, militar e de transição democrática e os modelos de planejamento, partindo do pressuposto que o planejamento social emerge na América Latina como instrumento para a formulação de políticas sociais. Trataram, ainda, de considerar algumas tendências do Planejamento na América Latina destacando o Enfoque Estratégico da Programação em Saúde, formulado pela Escola de Saúde Pública de Medellín; o Pensamento Estratégico elaborado por Mario Testa; e o Planejamento Estratégico Situacional desenvolvido por Carlos Matus.

UNITERMOS: planejamento, políticas sociais

\section{1 - INTRODUÇÃO}

O objetivo deste texto é fazer algumas considerações sobre a relação entre as políticas sociais e os modelos de planejamento. Partimos do pressuposto que o planejamento social emerge na América Latina como um instrumento para a formulação das políticas sociais.

\footnotetext{
* Professor Assistente do Departamento de Enfermagem Materno-Infantil e Saúde Pública da Escola de Enfermagem da Universidade Federal de Minas Gerais

** Professor Doutor do Departamento de Enfermagem Geral e Especializada da Escola de Enfermagem de Ribeirão Preto da Universidade de São Paulo
} 
A explicação para os determinantes das políticas sociais tem convergido para as necessidades de acumulação de capital e legitimação do Estado, entretanto, segundo TEIXEIRA ${ }^{10}$, tem um caráter restrito, uma vez que não incorpora duas ordens de fatores:

" $1^{\circ}$ ) que a política social é a resultante possível e necessária das relações que historicamente se estabeleceram no desenvolvimento das contradições entre capital e trabalho, e ao mesmo tempo, é fator determinante no curso posterior da relação entre as forças sociais;

$2^{\circ}$ ) que para o campo das políticas sociais confluem interesses de natureza diversa e mesmo contraditórios, advindos da presença de atores na cena política, de sorte que a problemática da emergência da intervenção estatal sobre as questões sociais encontra-se multi-determinada."

Nessa perspectiva é que enxergamos o processo da reforma sanitária: um espaço onde estarão em luta os interesses hegemônicos, expressos pela corrente neoliberal, e os interesses dos trabalhadores e profissionais de saúde voltados para a construção de uma contra-hegemonia na saúde através da luta pela consolidação da democracia, da cidadania e da montagem de um novo modelo assistencial baseado nas diretrizes propostas pela $8^{a}$ Conferência Nacional de Saúde ${ }^{1}$.

Para o momento da construção da democracia e de um novo modelo assistencial é necessário discutir as tendências que o planejamento em saúde deverá tomar: passando de um modelo normativo, que privilegia as questões técnicas e econômicas, a partir de uma aparente neutralidade, e que não dá conta das demandas geradas no Processo de Reforma Sanitária, para modelos que tragam na sua concepção a incorporação da necessidade de transformação social, construindo formas de valorizar os aspectos políticos e sociais.

\section{2 - POLÍTICAS SOCIAIS: ALGUMAS CONSIDERAÇÕES SOBRE SUAS FORMULAÇÕES E OS MODELOS DE PLANEJAMENTO}

As políticas sociais, segundo TEIXEIRA ${ }^{10}$, podem ser compreendidas a partir da identificação das relações entre o Estado e a Sociedade, em 3 níveis: "ao nível econômico, através das diferentes necessidades de reprodução ampliada do capital que incidem ou se realizam através do setor saúde; ao nível político, ao compreender as políticas de saúde como parte do processo de legitimação do poder do Estado e, conseqüentemente, da manutenção do domínio de classe; e ao nível ideológico, ao desvendar as articulações entre a produção científica, as práticas sociais e o conjunto de valores que organiza o universo cultural e moral dos profissionais de saúde, com a inserção desses agentes na estrutura social". 
Para $\mathrm{LUZ}^{4}$, as políticas de saúde desempenharam um papel histórico fundamental para a estabilização e constituição da ordem política e social, ajudando a modelar alguns traços dessa ordem como "a tendência à concentração do poder e exclusão das classes populares dos sistemas de decisão econômicas política e culturais do País".

No processo de formulação de políticas sociais, pode-se agrupá-las em 3 grupos distintos de acordo com os regimes políticos que as gestaram. Apresentaremos uma síntese do significado e conteúdo dessas políticas em relação à saúde nos regimes populistas, militares e de transição democrática, procurando articular as idéias centrais dos modelos de planejamento econômico-social que se desenvolveram e as tendências para as próximas décadas.

\section{1. - Políticas sociais nos regimes populistas}

Nesses regimes, as políticas sociais caracterizaram-se por ser, ao mesmo tempo, um sistema de exclusão política e social de certos grupos populacionais (trabalhadores rurais, domésticas, autônomos, dentre outros); um sistema de privilégios diferenciais para os grupos mais poderosos; e um mecanismo institucional, administrativo e legal fragmentado, múltiplo e diversificado.

Houve uma crescente politização das relações sociais e o mecanismo previdenciário, através da criação das Caixas e Institutos de Aposentadoria e Pensões, foi fundamental na cooptação de frações de trabalhadores ao projeto estatal, funcionando também como canal efetivo de escoamento da demanda política e social desses grupos ${ }^{10}$.

A formulação dessas políticas baseou-se no que TEIXEIRA ${ }^{9}$ denominou de "Ideologia do Desenvolvimento", onde a intervenção do Estado na economia foi colocada como condição essencial para um desenvolvimento rápido. Esta ideologia apoiou-se fundamentalmente no nacionalismo e na política de substituição de importações face ao processo de industrialização emergente.

O planejamento econômico-social emerge na América Latina na década de 50, apoiado numa doutrina que faz do planejamento um instrumento indispensável à racionalização do processo de substituição econômica e de acumulação de capital. Essa doutrina é gerada pela CEPAL - Comissão Econômica para a América Latina, que constata a necessidade da intervenção do Estado na economia a fim de melhorar as relações de troca entre os países periféricos e centrais ${ }^{7}$.

\section{2. - Políticas sociais nos regimes militares}

Nesse período, ocorreu uma nova configuração política, caracterizada pela exclusão política e econômica dos setores populares, desmobilização e despolitização da sociedade. A exclusão dos trabalhadores do novo pacto de poder e a desmobilização através de violenta repressão às suas organizações refletiram-se 
nos aparelhos de política social através da maior ou menor intervenção estatal no sistema previdenciário com o conseqüente afastamento dos trabalhadores de sua direção ${ }^{10}$.

Os interesses privados passaram a se incrustar nos aparelhos de políticas sociais, onde a crescente intervenção estatal na assistência médica foi o mecanismo que possibilitou a privatização da política pública.

Houve uma reorientação da política nacional de saúde prevalecendo uma prática médica curativa-individual, onde as medidas de saúde pública de caráter preventivo e de interesse coletivo passaram para um plano secundário. Desenvolveuse um padrão de prática médica orientado em termos de lucratividade, propiciando a mercantilização e empresariamento da medicina, viabilizando a formação de um complexo médico-industrial.

$\mathrm{Na}$ área de saúde pública, adotaram-se políticas de extensão de cobertura baseadas no ideal da medicina comunitária, através da utilização extensiva de mão de obra desqualificada, profissionais generalistas e tecnologias simplificadas.

Este modelo privatista de assistência não foi capaz de alterar o perfil de morbimortalidade e entra em crise, dado o aumento dos custos que dificultava a expansão da rede, a ausência de critérios para compra de serviços e alto grau de centralização e fragmentação das ações em dois ministérios.

Essa crise do modelo foi favorecida pela crise financeira do Estado, pela recessão na América Latina e pelo processo de redemocratização que colocou novas exigências (demandas) à dívida social.

A idéia de planejamento deste período foi aquela oriunda das recomendações internacionais que se materializaram em planos nacionais, no caso da Europa de reconstrução nacional, e no caso da América Latina, a partir da Reunião da OEA Organização dos Estados Americanos (realizada em Punta Del Este, em 1961) de planos de planejamento do social tendo em vista garantir a continuidade do processo produtivo, dada a crise econômica que se instalou com o fracasso da política de substituição de importações. "O Desenvolvimento deixa de ser visto como um processo dependente apenas do crescimento econômico e passa a ser olhado como um processo global, a incluir as estruturas políticas e sociais" ${ }^{\text {. }}$.

O planejamento teria o papel de transformar racionalmente as estruturas, reformando as instituições, seja no campo da saúde, educação, no regime de propriedade da terra ou na administração pública.

$\mathrm{Na}$ saúde, elaborou-se em 1965, com o apoio da OPAS e a partir de Mario Testa, o chamado Método CENDES/OPAS (Centro de Estudos para o Desenvolvimento Econômico e Saúde) que se constitui num método de programação sanitária, onde o desenvolvimento de métodos e técnicas de programação social impunham mudanças racionalmente planejadas como alternativa para a crise social. Esse método, também denominado de planejamento normativo, representa o marco inicial do desenvolvimento do planejamento em saúde na América Latina.

A lógica interna do método é economicista e administrativa, mais voltada 
para o crescimento do que para a eqüidade. Baseia-se na idéia da eficiência na utilização dos recursos disponíveis.

Como principais características, RIVERA ${ }^{7}$ aponta as seguintes:

- aplicação da visão ecológica do processo saúde/doença para a aplicação do diagnóstico;

- a questão das prioridades é tratada de acordo com a análise custo/benefício, numa perspectiva economicista;

- o uso da combinação ótima dos recursos tendo em vista aumentar a eficiência na prestação de serviços, em termos de uma quantidade maior de atos produzidos e de um barateamento de custos. Percebe-se aí a idéia de normatização do rendimento e da composição quantitativa do instrumento, coincidindo com os pressupostos "tayloristas" de uma produção-padrão. Influência que observamos de forma marcante também na administração hospitalar, onde a racionalização dos recursos estimulou a divisão técnica do trabalho, o movimento pela padronização e a elaboração de normas e procedimentos rígidos;

- perspectiva sistêmica de análise, onde se supõe que a técnica programática pode se superpor ao nível da definição política até o ponto de suplantá-la.

Para ROCHA ${ }^{8}$, a técnica CENDES/OPAS, além de "naturalizar" o social, ou seja, tratar o social igual aos objetos das ciências naturais, não aclarando as causas sociais dos problemas que enfrenta, também considera que "a realidade cientificamente estudada fornece fundamentos suficientes para orientar a racionalização do setor e a definição de políticas. A política antecede e determina o planejamento e há nítida separação entre a esfera do planejamento (técnica e a do político), com a qual a programação em saúde não deve confundir-se".

\section{3. - Políticas sociais e transição democrática}

Como processo de redemocratização do Estado a questão da reforma sanitária, que já vinha sendo posta na pauta das lutas sociais, ganha impulso com a convocação da $8^{\mathrm{a}}$ Conferência Nacional de Saúde. Esta conferência, dado o seu caráter democrático de convocação, delineia o arcabouço da reforma sanitárias brasileiras, que mais tarde é legitimado com a promulgação da nova Constituição, em 1988. Neste sentido, a reforma adquire, segundo $L U Z^{4}$, um papel não somente ligado à organização dos serviços de saúde num sistema único regionalizado e hierarquizado, mas também no estabelecimento de uma ordem social democrática que contribui para situar a política de saúde como elemento de importância fundamental na presente conjuntura de estabilização da ordem política.

Para TEIXEIRA ${ }^{10}$, a "reforma" sanitária é um processo político de transformação da norma legal e do aparelho institucional que regulamenta e se responsabiliza pela proteção à saúde dos cidadãos e corresponde a um efetivo deslocamento do poder político em direção às camadas populares no sentido de concretizar o direito universal à saúde e na criação de um Sistema Único de Saúde 
sob a égide do Estado". Esta autora coloca alguns elementos que merecem ser impulsionados no processo da reforma sanitária, destacando os seguintes: ampliação da consciência sanitária; construção de um paradigma analítico oriundo da saúde coletiva e organizado a partir das noções de determinação social do processo saúde/doença e da organização da prática; desenvolvimento de uma nova ética profissional; construção de um arco de alianças políticas na luta pelo direito à saúde; criação de instrumentos de gestão democrática e controle social sobre o sistema de saúde.

Estes elementos diferenciam o processo da reforma sanitária da criação dos mecanismos de proteção social denominados "welfare state", além do mais a conjuntura recessiva constitui obstáculo aos países latino-americanos em implementar esses mecanismos de proteção. O "welfare state" esteve ligado a um ciclo ascendente da economia na Europa e ao predomínio de uma ideologia social-democrata ${ }^{10}$.

No caso brasileiro, o processo da reforma sanitária procura trabalhar, ao nível estratégico, com 3 conceitos fundamentais que passam a constituir-se no processo político de construção do saber, conforme TEIXEIRA ${ }^{10}$ :

- conceito de saúde: passagem de uma conceituação abstrata de saúde como "estado de completo bem estar físico, mental e social..." para a busca de uma aproximação cada vez maior da complexa realidade. Saúde define-se num contexto concreto histórico de determinada sociedade e num dado momento de seu desenvolvimento, devendo ser conquistada pela população;

- saúde como resultado das formas de organização social da produção, mas sempre como fruto das lutas populares cotidianas. As questões que se colocam hoje dizem respeito às condições necessárias para o processo de democratização da saúde. A democracia passa a ser vista como o espaço ideal de formulação de uma contrahegemonia, constituindo no locus de articulação das mediações entre Estado e Sociedade, e a cidadania é a mediação que dá organicidade a esta relação;

- cidadania que envolve tanto o direito, por um lado, de ser tratado pelos outros seres humanos como um igual no que refere a fazer escolhas coletivas e, por outro, o dever por parte dos que implementam tais escolhas, de ser acessível e responsável perante todos os membros da comunidade política. Desta forma, TEIXEIRA ${ }^{10}$ discute a necessidade de se ultrapassar o momento da abstração do conceito de cidadania, pois assim implica numa igualdade formal entre os indivíduos isolados perante o Estado, gerando um efeito de mascaramento da existência das relações contraditórias de exploração, deixando de ser mais uma mistificação da relação de igualdade burguesa, ao negar a existência das classes sociais.

A forma e o conteúdo da reforma sanitária brasileira vai depender em última instância da ocorrência e articulação de algumas condições; que contribuem, segundo TEIXEIRA ${ }^{10}$, para a construção de um bloco histórico e contra-hegemônico:

- desenvolvimento da consciência sanitária, ao mesmo tempo como consciência de cidadão. Possibilidade que se apresenta na dualidade representada pela incidência da saúde/doença, enquanto processo coletivo, em indivíduos isolados; 
- convergência de interesses policlassistas, envolvendo pelo menos os trabalhadores, a população organizada, os intelectuais, parcela dos profissionais e burocracia estatal. Há a necessidade de se criar arcos de alianças políticas necessárias para a transposição do nível corporativo de organização de cada grupo específico em direção a um projeto globalizante;

- existência de um acervo de conhecimentos necessários não só à explicação dos fenômenos saúde/doença como à transformação efetiva do perfil epidemiológico prevalente e da atual organização social da prática médica;

- interpretação do conteúdo administrativo. O eixo não está dado ao nível dos próprios processos administrativos, mas ao nível do poder político. Toma-se necessário desvendar as articulações entre o planejamento, como instrumento privilegiado, mas não exclusivo da burocracia, e o processo de transformação social.

Para a viabilização/atendimento das demandas colocadas cabe refletir um pouco sobre algumas tendências do planejamento em saúde na América Latina. Tendências que propõem o privilegiamento da visão política na formulação e execução de programas na tentativa de superação da limitação imposta pelo planejamento Normativo e que possa, estrategicamente, encaminhar as questões acima colocadas e outras mais específicas neste campo como as mudanças necessárias na gestão institucional, de forma a elevar a qualidade dos serviços; e os conflitos gerados a partir da reforma sanitária com os diversos atores sociais envolvidos, destacando aí os interesses do setor privado e da corrente neo-liberal e os setores sociais comprometidos com o ideário da reforma.

Por outro lado, contraditoriamente, destaca-se que é justamente nesse período de transição democrática que o Planejamento Normativo constitui-se e consolida-se como modelo dominante de Planejamento em Saúde.

\section{3 - TENDÊNCIAS DO PLANEJAMENTO NA AMÉRICA LATINA}

Na América Latina desenvolvem-se atualmente 3 tendências de planejamento que contrapõem o modelo dominante do planejamento normativo em saúde os quais criticam basicamente o privilegiamento da lógica economista e, administrativa no estabelecimento de prioridades é privilegiam o planejamento, como instrumento no processo de transformação. São as seguintes: Enfoque Estratégico da Programação em Saúde: formulação feita pela Escola de Saúde Pública de Medellín, 1975; Pensamento Estratégico: elaborada por Mario Testa, sanitarista argentino, 1981; Planejamento Estratégico Situacional: elaborada por Carlos Matus, economista chileno, 1982. 
Todas as 3 propostas partem de uma visão política do planejamento em que o ator que planeja está imerso na realidade planificada. Explicitaremos em seguida os aspectos principais dessas tendências, sem, contudo, neste texto, aprofundar as suas divergências metodológicas.

\section{1. - Enfoque estratégico da programação em saúde}

Essa tendência, apoiado pelo documento "Formulación de Políticas de Salud (1975)", representou um novo paradigma para explicar o setor saúde, a sociedade e a relação entre ambos, ao reconhecer a política como uma das esferas do social e que requer meios específicos para o seu estudo. O documento, elaborado pela CPPSOPAS - Centro Pan-Americano de Planificação em Saúde da OPAS, pretendia colaborar com conceitos e orientações sobre a formulação de políticas de saúde e concebia o sistema de saúde a partir de 3 componentes: o político, o técnico-político e o nível técnico-operacional ${ }^{8}$.

O modelo básico, segundo RIVERA ${ }^{7}$, prevê as seguintes etapas:

a) formulação de uma imagem-objetivo (IO), de natureza político-ideológica e alicerçada tecnicamente no diagnóstico de situação;

b) comparação entre a $\mathrm{IO}$ e a situação inicial (SI), identificando na SI as falhas, as carências e obstáculos que se opõem ao cumprimento da imagem-objetivo. É o momento da identificação do hiato existente entre a situação inicial e a imagemobjetivo, que deverá ser superada com as políticas e uma estratégia;

c) definição dos projetos preliminares (proposições ou políticas) a partir da identificação dos problemas prioritários da situação inicial e das soluções prioritárias.

A priorização deve se dar fundamentalmente por critérios políticos;

d) análise de factibilidade e de coerência de tais projetos e retroalimentação estabelecendo um caráter dinâmico ao processo;

e) análise de viabilidade, incluindo também o caráter dinâmico através da retroalimentação;

f) definição de uma estratégia ou de um conjunto de projetos definitivos (programa direcional-arco direcional) e de sua trajetória;

g) formalização e implementação.

Este modelo apóia-se em estudos metodológicos de MATUS ${ }^{5}$ que veremos mais especificamente colocados quando da apresentação do modelo da planificação estratégica. 0 grande mérito deste enfoque é ter contraposto, em 1975, à visão dominante do planejamento Normativo, resgatando o caráter dinâmico, flexível, atrelado à conjuntura do planejamento e a importância do reconhecimento de que 0 planejamento envolve o enfrentamento e confluência das forças sociais. "A ação dos grupos sociais e o significado que adquire a interação entre eles através dos aspectos formais, materiais ou organizativos podem pelo seu caráter "objetivo" ser tratados tecnologicamente" ${ }^{\text {. }}$.

Para $\mathrm{ROCHA}$, "o método não pretende interpretar a realidade para obter 
a explicação das ações sociais, mas fazer uma avaliação do cenário social para desenvolver a melhor estratégia no sentido de obter a viabilidade das propostas do setor".

Planejar passa a ser um ato político e cabe ao planejador reconhecer seu papel político, ser técnico, mas com competência política.

\section{2. - Pensamento estratégico}

Essa tendência atribui a necessidade de mudança ao âmbito da política em geral e tem uma visão de planejamento como instrumento capaz de auxiliar no cumprimento de uma única imagem-objetivo possível, a da acumulação e desacumulação de poder. Trabalha com três níveis de diagnósticos: o administrativo, o estratégico e o ideológico ${ }^{11,12}$.

Diagnóstico Administrativo: voltado para a análise dos recursos, do acesso populacional aos serviços, da estrutura populacional e da enfermidade, nos termos elementares da planificação normativa e associado ao propósito de aumentar a produtividade. Este diagnóstico envolve as seguintes categorias básicas:

- estado de saúde da população: morbidade, mortalidade, natalidade, sexo, idade, macrolocalização e outros indicadores;

- situação epidemiológica: refere-se às causas da doença, causalidade, risco, dentre outros. Trabalha com taxas e percentagens;

- serviços de saúde como uma das formas de resposta da sociedade aos problemas apresentados pelo estado de saúde e a situação epidemiológica, conforme a classificação dos serviços segundo modelo de História Natural das Doenças: primário, secundário e terciário. Trabalha com eficácia, eficiência e cobertura;

- estudo do setor saúde consistindo na análise de suas formas de organização e as relações interinstitucionais presentes no sistema de saúde.

Diagnóstico Estratégico: voltado para a análise das relações de poder (quem detém o poder, quem controla o financiamento, quem sai beneficiado ou prejudicado com uma determinada proposta política, como se dá o interesse de classe) e associado ao propósito da mudança. Aqui se estudam as relações de poder em nível das categorias básicas: estado de saúde da população, situação epidemiológica, serviços de saúde e setor saúde.

Diagnóstico Ideológico: procura identificar os aspectos técnico-ideológicos que conduzem à legitimação do poder como propósito e que são utilizados para a interpretação dos dois primeiros níveis de diagnóstico e para a imposição das idéias dominantes na sociedade. Esse diagnóstico visa identificar quais grupos sociais sustentam quais sistemas de idéias em relação ao processo saúde/doença paradigmas como, a multicausalidade e visão ecológica de LEAVELL \& CLARK. Este diagnóstico, por fim envolveria uma síntese diagnóstica, dinâmica e estratégica, onde seriam formuladas as propostas.

O pensamento estratégico em saúde admite 3 tipos de poder: o administrativo 
que envolve a gerência de recursos humanos, materiais e econômicos: o técnico, ligado ao conhecimento e saber e que vai determinar o novo administrador; e $\mathrm{O}$ político como o prioritário que envolve as forças sociais.

Para TESTA ${ }^{13}$, as maneiras como se combinam os tipos de poder e as formas assumidas apontam para possibilidades diversas, para os caminhos que se teria de percorrer na constituição de um poder político de classe, isto é, um poder político científico e hegemônico. Para o autor, em algum momento da dinâmica do poder, os poderes administrativos e técnicos ficam "subsumidos" no poder político. Para tanto, TESTA procura, com base em HABERMAS, "criar uma estrutura comunicativa que devolva ao povo as ferramentas científicas necessárias para sua libertação".

O trabalho de TESTA, segundo RIVERA ${ }^{7}$, tenta equacionar a lógica da programação em saúde a partir de uma ótica materialista, baseada parcialmente na Lei do valor. ROCHA ${ }^{8}$ admite que TESTA incorpora elementos do materialismo histórico, entretanto, de forma mecanicista, não Ihes dando o tratamento de categorias de análise dialética; além de assinalar alguns problemas na proposta como, por exemplo, a eliminação das variáveis "sociais" no diagnóstico administrativo e a ausência: de indicadores no diagnóstico estratégico, que possam refletir a estrutura de poder, não lhe permitindo chegar a identificaras mediações entre poder e organização.

\section{3. - Planejamento estratégico-situacional}

Este modelo trabalha com dois conceitos básicos: o de situação, com base fenomenológica e o da teoria da produção social de base marxista ${ }^{7}$.

O conceito de situação significa o lugar social onde está situado o ator e a ação. Fundamenta a premissa da existência de uma plural idade explicativa de acordo com o número de atores envolvidos. Denota o olhar de um ator envolvido na realidade que pretende explicar e que está determinado pela situação.

A teoria da produção social, elaborada por KOSIC, apud RIVERA ${ }^{7}$, sustenta que a explicação situacional dos problemas deve ser feita em dois planos interrelacionados:

- plano fenomênico ou da produção dos fatos, tal qual são percebidos na superfície;

- plano das essências ou das estruturas determinantes dos fenômenos, que envolve dois outros planos: fenoestruturas ou acumulações de poder (organizações sociais, econômicas e ideológicas, incluindo o Estado) e genoestruturas ou das leis básicas que regulam uma formação social (modo de produção e classes sociais) e que determinam em última instância.

A aplicação concreta dessa teoria visa estabelecer a cadeia de relações que os problemas estabelecem com as acumulações de poder e com a legalidade básica 
do sistema de modo a se estabelecer uma hierarquia causal e a favorecer uma atuação mais totalizante, e, portanto, mais efetiva.

MATUS ${ }^{5}$ prevê 4 momentos básicos para o desenvolvimento de seu enfoque metodológico: o momento explicativo, o normativo, o estratégico e o tático operacional.

Momento Explicativo: onde se realiza a explicação dos problemas a partir dos conceitos de situação e de teoria da produção social - é o momento da explicação situacional hierarquizada.

Momento Normativo: correspondente à definição do "dever ser" do plano, das operações que enfrentarão os problemas (operações versus problemas), o que poderia se chamar de "situação-objetivo".

Momento Estratégico: é o momento de "poder ser" e ao "como fazer". Inclui a formulação de uma estratégia e a análise de viabilidade em 3 níveis:

- viabilidade política: estratégias de cooperação que supõe negociações para acordar vias comuns de ação através de renúncias recíprocas, onde um ator ganha a adesão do outro à sua própria posição; e onde o conflito serve de campo para os atores medirem, em conjunto, o peso de seus projetos;

- viabilidade econômica: deve responder se os projetos políticos, econômicos e organizativos são viáveis economicamente;

- viabilidade institucional-organizativa: terá de responder se a capacidade organizativa é capaz de sustentar o programa direcional, se temos capacidade de melhorar a organização institucional e ainda, se a nova organização desenhada para cumprir o plano é viável e eficaz.

Momento Tático-operacional: correspondente à planificação conjuntural ou à programação de curto prazo, ou seja, à desagregação das grandes diretrizes do plano e ao seu referenciamento à conjuntura, incluindo tomada de decisão, controle e avaliação. Sua importância reside no fato de que não existe ação no futuro desejado, assim, o presente nos permite "fazer" e o futuro nos assinala o "dever ser". Esse momento admite outros dois momentos: a instância do conhecimento, relativa à apreciação da situação na conjuntura e a instância da ação que corresponde à atuação sobre problemas e operações.

Uma crítica importante ao trabalho de MATUS vem de $\mathrm{ROCHA}^{8}$, e diz respeito fundamentalmente a uma questão de ordem epistemológica, o tratamento que é dado ao social: "pretende ser possível construir modelos físico-matemáticos de previsão da ação social, antes dos acontecimentos e, assim, fundamentar o seu planejamento; incorre aqui, no nosso entender, em dois erros: os agentes sociais, ainda que filiados a grupos ou partidos políticos, freqüentemente só definem suas condutas no processo diante das alternativas postas e na forma colocada". Acrescenta ainda que MATUS desfaz o que seria o grande avanço do planejamento estratégico (a incorporação da dimensão política) quando reduz a política ao desvinculá-la das suas bases sociais e históricas. 


\section{4 - CONSIDERAÇÕES FINAIS}

Mesmo considerando os limites impostos, por nós, para o aprofundamento das questões colocadas neste texto, e o caráter dado de que seria uma primeira aproximação, julgamos oportuna finalizá-lo com algumas reflexões para o debate sobre esta problemática.

Entendemos que as questões críticas de base teórica, apresentadas por $\mathrm{ROCHA}^{8}$, merecem ser aprofundadas: o descompasso entre a teoria e prática no planejamento em saúde, ou seja, a ausência de correspondência entre a lógica dos modelos orientados pelas correntes sociológicas de pensamento com os métodos correspondentes para o estudo da realidade.

A questão central que se coloca no momento é desenvolver uma metodologia de planejamento que signifique efetivamente um instrumento de sustentação e continuação do processo da reforma sanitária. Para isto faz-se necessário ainda desenvolver melhor as questões epistemológicas do planejamento em saúde que possa sustentar novos métodos que irão, por sua vez, possibilitar, planejar em situações de conflito, transcendendo à visão clássica do planejamento em saúde: 0 Normativo.

O planejamento em saúde deve trabalhar para o resgate da função social do Estado e contrapor à ordem do projeto neoliberal para a saúde, através da criação de novos mecanismos de gestão ${ }^{3}$. Abrindo espaços para a democratização do setor saúde, reconhecendo os direitos do cidadão, incorporando suas necessidades, de forma a permitir, que o controle social sobre a produção dos serviços possa contribuir decisivamente para a construção de um projeto de transformação das práticas de saúde, articulando a eficácia, eficiência e efetividade das ações de saúde. Para tanto, os trabalhadores da saúde devem se colocar como sujeitos desse processo, incorporando o conceito de cidadania.

O planejamento, para $\mathrm{CAMPOS}^{2}$, deve contribuir na formação de um novo perfil de gerência dos serviços de saúde, estabelecido em bases epidemiológicas e no diagnóstico de necessidades de saúde, a ser utilizado como instrumento determinante para a destinação dos recursos técnicos e financeiros. Além disso, o autor levanta a necessidade de ordenar a produção de serviços de saúde, buscando incorporar a atenção médica curativa à rede básica, mas, subordinando-a a lógica decorrente da saúde pública.

Concordamos com MENDES ${ }^{6}$, quando afirma que "a gerência deve ser orientada para o ambiente externo e adaptável às mudanças demográficas, epidemiológicas, culturais, econômicas e sociais, onde se valoriza o trabalho multidisciplinar, tudo isso perpassado por uma ética que privilegie o interesse do cidadão". 


\section{REFLECTIONS ABOUT THE HEALTH PLANNING AND THE PROCESS OF SANITARY REFORMS IN BRAZIL}

The authors considered carefully the Brazilian social policies at the regimes of populism and militarism as well as at the democratic transition following the presupposition that the social planning in Latin America emerged as an instrument for social policies formulation. The authors also considered some tendencies of the Latin America Planning emphasizing the Strategic Focus of the Health Program formulated by the Public Health School of Medellin; the Strategic Thought elaborated by Mario Testa; and the Strategic Situational Planning developed by Carlos Matus.

UNITERMS: planning, social policies

\section{REFLEXIONES SOBRE EL PROYECTO EN LA SALUD Y EL PROCESO EN LA REFORMA SANITARIA BRASILEÑA}

En este trabajo, los autores buscaron desarrollar algunas ponderaciones acerca de las formulaciones de la política social brasileña, en los regimenes populistas, militares, los llamados de transición democrática y los modelos de planificación, con la premisa de que el proyecto social emerge en América Latina como un instrumento para la formula de políticas sociales. Se trató además, considerar alunas tendencias de la planificación en América Latina sobresaliendo el Enfoque Estratégico de la Programación en Salud, formulados por la Escuela de Salud Publica de Medellín, el Pensamiento Estratégico elaborado por Mario Testa; y la Planificación Estratégico Situacional desarrollado por Carlos Matos.

UNITERMOS: planificación, políticas sociales

\section{REFERÊNCIAS BIBLIOGRÁFICAS}

01. BRASIL, MINISTÉRIO DA SAÚDE. Relatório final da $8^{\text {a }}$ Conferência Nacional de Saúde. Brasília, 1986.

02. CAMPOS, G. W. de S. Considerações sobre o processo de administração e gerências de serviços de saúde. In: CAMPOS, G. et al. Planejamento sem normas. São Paulo: Hucitec, 1989. 
03. A saúde pública e a defesa da vida. São Paulo: Hucitec, 1991.

04. LUZ, M. T. Notas sobre as políticas de saúde no Brasil de "transição demográfica" - anos 80. Saúde Debate, n. 22, p. 27-32, 1992.

05. MATOS, C. Fundamentos da planificação situacional e os métodos do VII Plano da Nação. In: RIVERA, F. J. U. (org.) Planejamento e programação em saúde: um enfoque estratégico. São Paulo: Cortez/ABRASCO, 1989. p. 10749.

06. MENDES, E. V. "A crônica de uma morte anunciada" ou Nascimento, paixão, morte e ressurreição do INAMPS. Brasília, 1993./ mimeografado/

07. RIVERA, F. J. U. (org.). Planejamento e programação em saúde: um enfoque estratégico. São Paulo: Cortez/ABRASCO, 1989.

08. ROCHA, J. S. Y. Análise crítica dos modelos de planejamento em saúde na América Latina. Educ.Med.Salud, v. 26, n. 2, 1992.

09. TEIXEIRA, S. F. et al. Antecedentes da reforma sanitária: textos de apoio. Rio de Janeiro: ENSP/FIOCRUZ, 1988.

10. TEIXEIRA, S. F. Reflexões teóricas sobre democracia e reforma sanitária. In: TEIXEIRA, S. F. Reforma sanitária em busca de uma teoria. São Paulo: Cortez/ABRASCO, 1989. p. 17-46.

11. TESTA, M. O diagnóstico de saúde. Parte I. In: RIVERA, F. J. U. (org.) Planejamento e programação em saúde: um enfoque estratégico. São Paulo: Cortez/ABRASCO, 1989. p. 55-104.

12. Tendências em planificação. Parte II. In: RIVERA, F. J. U. (org.) Planejamento e programação em saúde: um enfoque estratégico. São Paulo: Cortez/ABRASCO, 1989.

13. TESTA, M. Pensar em saúde. Porto Alegre: Artes Médicas, 1992. 